Article

\title{
Assessment of Existing Photovoltaic System with Cooling and Cleaning System: Case Study at Al-Khobar City
}

\author{
Nader Nader ${ }^{1, *}$, Wael Al-Kouz ${ }^{1,2}$ and Sameer Al-Dahidi ${ }^{3}$ (I) \\ 1 Mechanical Engineering Department, Prince Mohammad Bin Fahd University, \\ Al Khobar 31952, Dhahran, Saudi Arabia; wael.alkouz@gju.edu.jo \\ 2 Department of Mechatronics Engineering, School of Applied Technical Sciences, German Jordanian \\ University, Amman 11180, Jordan \\ 3 Department of Mechanical and Maintenance Engineering, School of Applied Technical Sciences, German \\ Jordanian University, Amman 11180, Jordan; sameer.aldahidi@gju.edu.jo \\ * Correspondence: nnader@pmu.edu.sa
}

Received: 12 November 2019; Accepted: 16 December 2019; Published: 19 December 2019

check for updates

\begin{abstract}
There is no denial that renewable energy is considered to be the most cost-competitive source of clean power in many parts of the world. Saudi Arabia's vision 2030 aims at achieving the best by using different sources of renewable energy such as solar energy, wind energy, and others. The use of solar energy in particular for power generation will decrease the dependency on oil, and thus, decrease the greenhouse gasses. Solar panels efficiency tends to decrease with the accumulation of dust on their surface. Thus, a cleaning process requires assigning and employing labor, which increases the cost of running as well as high cost of machinery. The current study focuses on assessing and designing a simple auto self-cleaning system in order to improve the efficiency of the solar panel. The results showed that for the Al-Khobar region, Eastern Province, Kingdom of Saudi Arabia, the efficiency of the solar panels after cleaning was increased from $6 \%$ to an average of $12 \%$ at nominal temperature of $27^{\circ} \mathrm{C}$. In addition, the average power output was increased by $35 \%$ during the day time. In addition, the normal efficiency of the solar panels before cooling was between $10 \%$ to $15 \%$ at $42{ }^{\circ} \mathrm{C}$. After cooling, the temperature of solar cells decreased to $20^{\circ} \mathrm{C}$ and the efficiency increased by $7 \%$. Moreover, the output power was increased by $31 \%$ with maximum efficiency of $32 \%$ at noon time.
\end{abstract}

Keywords: renewable energy; photovoltaic systems; cooling; cleaning; efficiency; real case study

\section{Introduction}

Solar energy is the cleanest and most abundant renewable energy source available, and the U.S. has some of the richest solar resources in the world. Solar technologies can harness this energy for a variety of uses, including generating electricity, providing light or a comfortable interior environment, and heating water for domestic, commercial, or industrial use. For example, the total installed U.S. Photovoltaic (PV) capacity is expected to more than double over the next five years, and by 2023, over 14 gigawatts (GW) of PV capacity will be installed annually [1].

Worldwide, there is an immense need of utilizing renewable energy; since we are rapidly depleting fossil fuels, there will soon come a time where we will be left with none to use. This gives us a challenge to look for other resources to generate electricity. One of the most reliable renewable energy sources is the sun and the energy it emits. The technological advances are becoming more effective in converting the solar energy into electricity using solar panels. However, more improvements are needed in order to increase the efficiency and decrease the cost of operation and maintenance. 
The Kingdom of Saudi Arabia has an impressive natural potential for solar and wind power, and the local energy consumption will increase threefold by 2030. However, there is still a lack of study cases and data on the performance of existing systems in the harsh desert weather that has a detrimental effect on efficiency. Saudi Arabia holds great potential in harvesting solar energy as sunshine is available all year round. The challenge of moderating power misfortune in solar PV system because of dust has become critical in the economical deployment of solar panels in dry districts. These territories experience the ill effects of high airborne focus levels and incessant dust storms that lead to a gathering of a layer of dust on the surface of solar arrays.

Even though there is an impressive natural potential for solar and wind power, the local energy consumption will increase threefold by 2030, the Kingdom of Saudi Arabia (KSA) still lacks a competitive renewable energy sector at present. To build up the sector, the government has set an initial target of generating $9.5 \mathrm{GW}$ of renewable energy. The government will also seek to localize a significant portion of the renewable energy value chain in the Saudi economy, including research and development, and manufacturing, among other stages. From inputs such as silica and petrochemicals to the extensive expertise of our leading Saudi companies in the production of different forms of energy, the KSA has all the raw ingredients for success. As a result, plans will put this into practice with the forthcoming launch of the King Salman Renewable Energy Initiative. A thorough review including the legal and regulatory framework will allow the private companies to buy and invest in the renewable energy sector. To localize the industry and produce the necessary skillsets, the government encourages public-private partnerships. Finally, the KSA government will guarantee the competitiveness of renewable energy through the gradual liberalization of the fuels market [1].

Solar energy has now proved to be an external beneficial source not only for the environment, but also financially speaking. Additionally, due to the higher demand for renewable energy, our article aims to turn it into an efficient source of clean energy. A solar sector is emerging as part of Saudi Arabia's economic diversifications plans under the vision 2030. Nowadays, most of the countries have started to rely on solar energy in their future plans. The study aims to increase the efficiency of solar energy. The solar panel efficiency is normally affected by extreme temperature conditions. The efficiency as specified by the manufacturer decreases by $0.5 \%$ for every one Celsius increase beyond $24^{\circ} \mathrm{C}$. The main challenge of this investigation is to keep the solar panel from heating and connecting it to a refrigeration system. The second challenge is to keep the water in the coil very cold by using anti-freezing liquid. This study objective is to design and manufacture a solar panel intercooled by a refrigeration system.

This project aims at reducing the use of fuel energy and to achieve one of the Saudi vision's objectives. The following explanation shows the mechanical process in details with the steps in operating the solar-powered refrigerator. In addition, economic benefits are achieved from using the refrigerator in the Saudi market with enough safety at a low cost as well. The project adds values to mechanical operation equipment and supports the environment with green energy and a suitable alternative to the fuel energy.

Similar work had been done before in previous research, where solar energy was used to supply enough power to a refrigerator with a simple mechanical operation. In this project, it is normal to have appropriate specifications for the vapor compression refrigerator. There are basic electrical and mechanical principles that support the mechanical operation for the advantages of using a high-quality solar-powered refrigerator. That work depended on the quality of making use from the evaporator compression in the refrigeration cycle. This may require appropriate percentage from the pressure needed to operate the mechanical system for both of the pumps and the operating system for the compression [2].

Since chilled water is going to be used in the proposed system, the typical refrigeration system with all the computations can be found in [3].

It is considered to have more innovation about the importance of using different types from solar-powered refrigeration. Using the different machines to get the absorption refrigeration type can 
support the process of solar refrigeration in general. This type is considered one of the heat driven types that supports the refrigeration process and increases the options of using solar refrigeration. It is important to mention that this paper does not propose a new invention in this field. However, there is a big development in the field of refrigeration in terms of energy and economic benefits. It was also considered to use the heat driven system as little as possible for mechanical power, which provides more than enough solar energy for other purposes. While the absorption system in refrigeration uses ammonia over using refrigerant and absorbent, it is necessary to accept the output mechanical power [4].

Throughout the scope of this work, electrical power was needed for starting the compressor and the water pump which were supplied partially by the solar panels. The compressor comes in the place of the absorption system to use three heat exchangers. One of those exchangers is the regenerating intermediate heat; another exchanger is the absorber. The last is the generator. The pumping process in this project is one of the main parts that sends cold water to the mechanical part of the solar panel to reduce its heat and to average the level of temperature in the refrigerator. The solar-powered refrigerators seem complicated and costly, while some others find that the conventional vapor compression systems are more complicated and more costly because they use electricity and other types of non-environmental energy. It may be necessary to use solar energy in appropriate methods, namely, using solar energy for simple items with simple electrical support. There are some procedures to keep enough solar energy to operate the refrigerator from the shapes that collect solar energy for mechanical power in the mechanical system in the solar refrigerator. In addition, the ability of a solar refrigerator system under the process of solar energy and the quality of the mechanical power in the whole system is examined.

The main idea of the discussion is that the new solar-powered refrigerator uses suitable power from different resources as compared to only fuel energy. The major advantage of solar refrigeration is that it can be designed to operate independently of a utility grid. Applications exist in which this capability is essential, such as storing medicines in remote areas [1].

Solar panels are clean sustainable power source using sunlight and convert that light into power, which is then able to be utilized to give capacity to electrical loads. Solar panels contain several individual solar cells that are themselves made out of layers of silicon, phosphorous, which gives the negative charge, and boron, which gives the positive charge. Solar panels ingest the photons, and in doing so, start an electric flow. The subsequent vitality produced from photons striking the outside of the solar panel enables electrons to be thumped out of their nuclear circles and discharged into the electric field created by solar cells, which at that point maneuver these free electrons into a directional flow. This whole procedure is known as the Photovoltaic Effect.

One of the main objectives of this study was to provide an automatic dust cleaning system to improve the efficiency of the solar panel. In most cases, cleaning was done physically. This manual cleaning has many disadvantages, such as accidents generated by minor mishaps, damaging of the panel surface, development challenges, poor support, and so on. The programmed residue cleaning arrangement of solar panels has been taken to defeat the troubles that emerge in customary cleaning. Furthermore, it delivers a compelling, non-abrasive cleaning and avoids the inconsistencies in the efficiency because of the deposition of dust.

Several researchers have conducted research on the viability of cleaning solar panel, utilizing a mechanized automated cleaning system [5]. The automated cleaning framework is a piece of an examination program identified with robotic dust relief advancements for solar panels, and incorporates another kind of brush, which utilizes silicone elastic froth folds mounted onto an aluminum center. The investigation found that the robotic system, utilizing this silicone elastic froth brush, could adequately limit the effect of dust on the solar panel capacity yield, giving an expansion in power yield versus the week after week cleaned controls. This new brush demonstrates guarantee for use in solar panel dust moderation because of its viable cleaning execution and low cost, and does not prompt any harm to the outside of the sun oriented board. 
More studies that have been conducted led to an exploration of various advancements, utilizing programmed cleaning systems for solar panels in various weather conditions. Solar photovoltaic systems have for some time been utilized to create vitality for various applications since the 1990s. The efficiency of solar photovoltaic model is dictated by the accessibility of the sun's radiance alongside different natural components, such as humidity, temperature, dust, snow, feces from flying animals, and so forth. The investigation showed that ecological factor did in fact diminishes the execution of the photovoltaic modules [6].

Previous comparative study of solar photovoltaic arrangements was completed in various settings. In their investigation, execution parameters of photovoltaic modules are checked continually in electrical terms, for example, voltage, flow, and power. In the interest of the acquired outcomes, an examination under various courses of action is made and it is seen that the photovoltaic system with cleaning and sun tracking system demonstrates best outcomes as compared to the stationary arrangement and sun following states of solar photovoltaic system. Overall, further study is valuable for residential based independent photovoltaic systems [7].

Another comparable research was conducted in this new cleaning component utilizing dew that was tried indoor with various kinds of wipers, distinctive cleaning angles and with various surface wetting times. The cleaning productivity with this instrument was exceptionally high; it achieved $99.3 \%$ for the ordinary single wiper, $98.9 \%$ for the industrial wiper, and $98.3 \%$ for the normal vehicle wiper. This system can spare huge amounts of water, and therefore, lead to a decrease in task and support cost. In any case, it must be viewed as that the system relies upon the dew potential of the Concentrated Solar Power (CSP) plant area, which is exemplarily researched for one solar site [8]. Other studies showed that dust gets accumulated on the front surface of the module and blocks the incident light from the sun. This reduces the power generation capacity of the module. The power output reduces as much as by $50 \%$ if the module is not cleaned for a month [9]. Further studies showed that in designing a self-directing system and in order to sense the physical parameters like dust and temperature of the solar panel.

Sensors were used to activate the wiper and dust is removed [10]. The dust usually gets accumulated on the front surface of the module, which blocks the sunlight. This reduces the power generation capacity of the module. The power output reduces as much as by $50 \%$ if the module is not cleaned for a month [11].

Another study was done within the kingdom that focused on increasing the efficiency of the photovoltaic panel for residential units. The design system provides enough energy by cooling the solar panels with pumping cool water from the refrigerator to the direct system. The results showed that for the Dhahran region, Saudi Arabia, the normal efficiency of the solar panels before cooling was between 10 to $15 \%$ at $42{ }^{\circ} \mathrm{C}$. After cooling, the temperature of solar cells decreased to $20{ }^{\circ} \mathrm{C}$ and the efficiency increased by $7 \%$. Moreover, the output power was increased by $31 \%$ with maximum efficiency of $32 \%$ at noon time [12].

Al-Kouz et al. [13] proposed a computational model to investigate the effects of dust and temperature on the performance of a photovoltaic system using Artificial Neural Network (ANN) [14] and Extreme Learning Machine (ELM) [15] models. They found that the optimized model predicts a conversion efficiency yielding an $\mathrm{R}^{2}$ of $91.4 \%$. Moreover, a literature review was done on the effect of natural dust and artificial dust on the performance of the photovoltaic system. The factors affecting the dust and its performance were discussed; it was shown clearly in their studies that there is a need for optimization, forecasting, and understanding of solar PV functioning, specifically unexplored factors such as soiling [13]. Additionally, an investigation on the performance losses due to dust through a dynamic study into the I-V characteristics of panels and their performance under varying soiling conditions was conducted by Rao et al. [16]. Moreover, Hammad et al. [17] studied effects of dust accumulation and ambient temperature on PV performance. The average efficiency reductions due to dust were $0.768 \%$ /day and $0.607 \%$ /day using MLR and ANN models, and the energy losses are $10.282 \mathrm{kWh} / \mathrm{m}^{2}$ and $8.140 \mathrm{kWh} / \mathrm{m}^{2}$. Furthermore, Beghanem et al. [18] showed the effect of dust 
accumulation on the surface of photovoltaic (PV) modules, which cause losses in their output power resulting in $28 \%$ of losses in output power at Madinah city during 60 days of dust accumulation. An intelligent cleaning system was proposed, using the notion of dust density, to start cleaning when an admissible value of power losses is reached. Finally, in their paper, Liu et al. [19] briefly summarized studies of dust deposition on PV panels of urban and desert areas in recent years, and analyzed the influence of dust deposition on the panel, particle characteristics and dust deposition process.

The main objective of this research was to design a feasible cleaning system to improve the efficiency of the solar panels within the environmental conditions at the Eastern province of the Kingdom of Saudi Arabia (KSA). The features of the system include removing both the dust and moisture accumulated on the PV panel surface. Moreover, the cooling system provided by chilled water will drop down the surface cell temperature of the PV system especially at extreme hot temperatures at the summer time. Combining all these features will ultimately improve the PV system efficiency. According to the author's knowledge, this state-to-art design is not being tackled by other researchers within the harsh conditions of the KSA eastern province region.

\section{Theoretical Calculations}

The performance of a PV cell is defined by the typical current-voltage (IV)-curve [20], which shows how the current inside the cell varies as a function of the voltage for a given solar irradiance. The current is proportional to the incident solar irradiance.

The power output is given by Equation (1):

$$
P=V \cdot I
$$

The heat input is given by Equations (2) and (3):

$$
\begin{aligned}
& Q_{\text {in }}=C_{v} \cdot m \cdot \Delta T \\
& Q_{\text {solar }}=\Phi \cdot A \cdot t,
\end{aligned}
$$

where $\Phi$ is the coefficient of heat transfer of the heating device $\left(\mathrm{W} / \mathrm{m}^{2}\right), A$ is heat transfer surface area of the heating device $\left(\mathrm{m}^{2}\right), \Delta T$ is the temperature difference $\left({ }^{\circ} \mathrm{C}\right), Q_{\text {in }}$ is the amount of heat generated in the cooling process of the solar panel, and $Q_{\text {solar }}$ is the amount of solar heat obtained during the day [20].

It is worth mentioning here that the measurements of the Direct Normal Irradiation (DNI) for Dhahran area, eastern province of Kingdom of Saudi Arabia, are reported in [21]. These values are taken into consideration for the current experimental work.

Finally, it should be reported here that there is extensive work has been done in order to enhance the efficiency of the Photovoltaic (PV) or the hybrid Photovoltaic/Thermal (PV/T) systems by dispersing the nano solid particles into the main base fluid. [22,23]. Authors will extend the work to include these technologies in the near future.

\section{Design Methodology}

In order for an automatic self-cleaning solar panel system to be effective, there are some constraints that should be taken in consideration. First, a major constraint is the weight. New parts and apparatus, such as brush, water sprinklers, batteries, pipes, and the AC motor attached to the solar panel, will add weight to the whole system. A waterless brush design was chosen for simplicity and its light weight. For the purpose to clean the tough dust adhered to the panel, we will be adding sprinklers that will be spraying very fine water droplets all over the panel. The system framework is constructed of aluminum to reduce the overall weight of the device. Second, the design system is required to function during the life of a solar panel. To make the system more cost productive, it needs to function for longer duration of time. Moreover, the device must be weatherproof, and thus, improving the battery 
life. Third, the sun emits energy at an extremely large rate hence there is abundant availability of solar energy for all year round. If all solar energy could be converted into usable forms, it would be more enough to supply the world's energy demand. However, this is not possible because of conditions in the atmosphere such as the effect of clouds, dust. and temperature. Solar energy can be converted to more usable energy forms through solar panels. There is unprecedented interest in renewable energy, particularly solar energy, which provides electricity without giving rise to any carbon dioxide emission. Fourth, traditionally, cleaning the system was done manually. The manual cleaning has disadvantages such as risk of staff accidents and damage of the panels, movement difficulties, and poor maintenance. The automatic self-cleaning system of solar panels is to overcome the difficulties arise in the traditional cleaning and also produces an effective, non-abrasive cleaning and avoids the irregularities in the productivity due to the deposition of dust. Automated self-cleaning solar panel is the need solar panel users either on large scale, i.e., organizations, street lights or smaller scale, i.e., households. Fifth, the financial considerations associated with the creation of the system are the largest constraint in the project. The manufacturing and operational costs of the system cannot exceed the financial savings from the improved solar panel efficiency. If the system cannot save enough money to offset its costs, there is no point in implementing the product in the first place. Furthermore, the system's unit cost must be low enough to attract potential customers. As a consumer product, the system is a significantly larger investment than the use of human laborers for solar panel cleaning. Any cost reductions will improve the chances of this product succeeding financially. In ideal conditions this system will operate for long periods of time, potentially longer than a decade. During this time, the system must maintain its cost effectiveness for its entire lifespan. Eliminating maintenance costs is critical to achieve this goal. Sixth and last, the system has also been planned to sustain safety at all times during its functional lifespan. The system is securely mounted to the solar panel, preventing it from becoming a falling hazard. The future addition of several sensors on board the device to initiate a shutdown would prevent the system from causing harm to any person or animal crossing into the path of the system. The whole system is planned to be waterproof and weatherproof in any situation to avoid any harm both to the solar panel and to its surroundings.

\section{Experimental Work}

The prototype setup consisted of a stand, solar panel, battery, controller, inverter, coil, compressor, condenser, expansion valve, evaporator, and refrigerator case. The first step was to calculate the internal heat coming from the sun and second to find the voltage and current for the current power output. The second step was to install additional parts, such as wipers, water filter, new tank, chains, humidity sensors, water jets, and a fan. The wipers (Anco, MI, USA) were attached above the solar panel and moved in a vertical motion. The system had a humidity sensor (Sensirion, Stafa, Switzerland) in order to activate the cleaning process when the humidity was abnormal. Third, the solar panel was installed above the stand, in which the coil (The coil is made of copper and is locally manufactured at Al-Khobar, KSA) was installed directly behind the surface of the solar panel. Moreover, the cooling tank was inserted inside the refrigerator (Absocold, Richmond, IN, USA). The coil that circulated the water to the panel was made of copper (7408 Copper Wire, the coil is locally manufactured at Al-Khobar, KSA). The refrigerator body was made of fiberglass to insulate the heat from going inside. In the refrigeration cycle, a reciprocating compressor (R134A 220V/50Hz 1/5HP $173 \mathrm{~W}$ Huaguang, Guangzhou, China) was used. In addition, to circulate the water passing through, the panel there used a water pump (Uniclife 80-550GPH Submersible Water Pump, Dammam, KSA). Moreover, the expansion valve that was connected to the evaporator used a CTV(E), DTV(E) series thermostatic expansion valve (Yueqincg Canto Refrigeration Equipment CO., LTD, Yueqing, Zhejiang, China) [9].

The PV panels used in the experiments are Trina TSM-PD14 polycrystalline (Trina, Cangzhou, China) with a peak power of $320 \mathrm{~W}$, maximum power voltage of $37.1 \mathrm{~V}$, and a maximum power current of $8.63 \mathrm{~A}$. 
In order to collect data from the self-cleaning solar panel system, evaluation of all important parameters was required to assess the systems performance. The voltage was being produced by the solar panels at three different stages when the sunlight was incident on the solar panels. First, the voltage was measured when the solar panel was cleaned by hand with no dust or humidity. Then, water was sprayed to simulate humidity, and the voltage was recorded. Finally, dust was placed on the panel, and new measurement were found. The same procedure was carried out and repeated five times at different hours of the day. In addition, the amount of power output from the voltage and current was measured for each trial $\left(P_{\text {out }}=V \cdot I\right)$, as were the power being produced and the power input, using $P_{\text {in }}=\varnothing \times$ Area. Thus, the efficiency of the system could be determined.

\section{Results and Discussion}

Figure 1 shows the assembly drawing of the system.

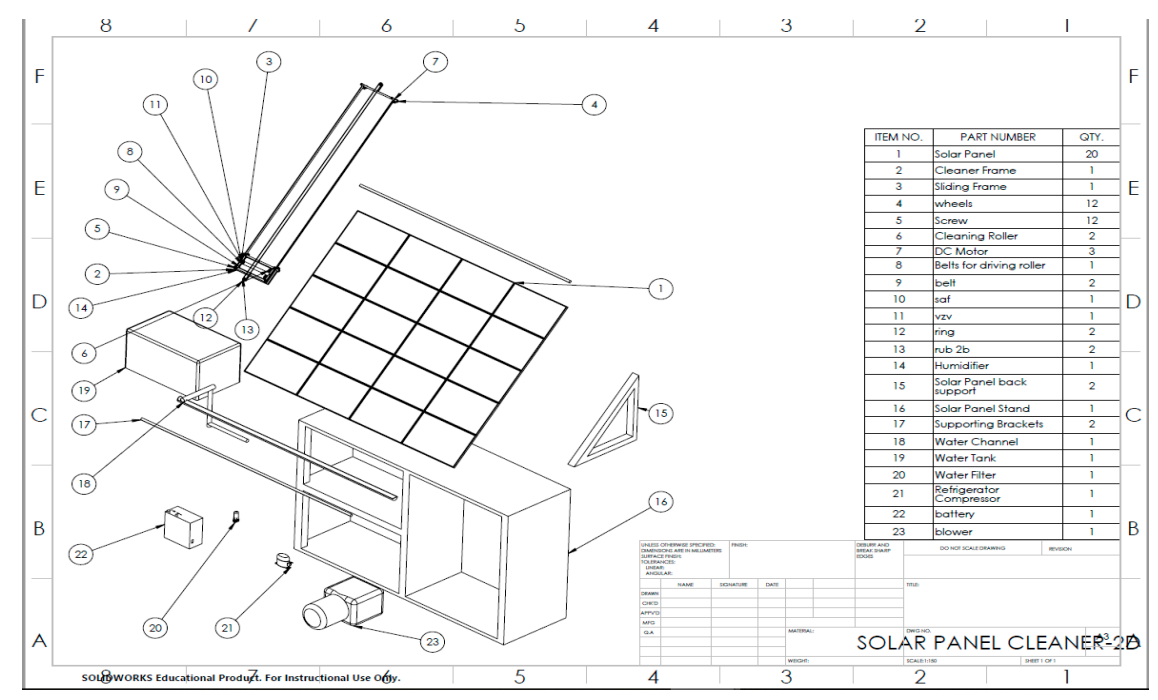

Figure 1. Assembly drawing of major parts used in this experiment.

Figure 2 shows the installed solar panel together with the cleaning system. It is worth mentioning here that the cleaning rate, i.e., the time of movement of the cleaning components is measured and found to be $8 \mathrm{~s}$. The amount of dust covering the solar panel triggered the cleaning system to start.

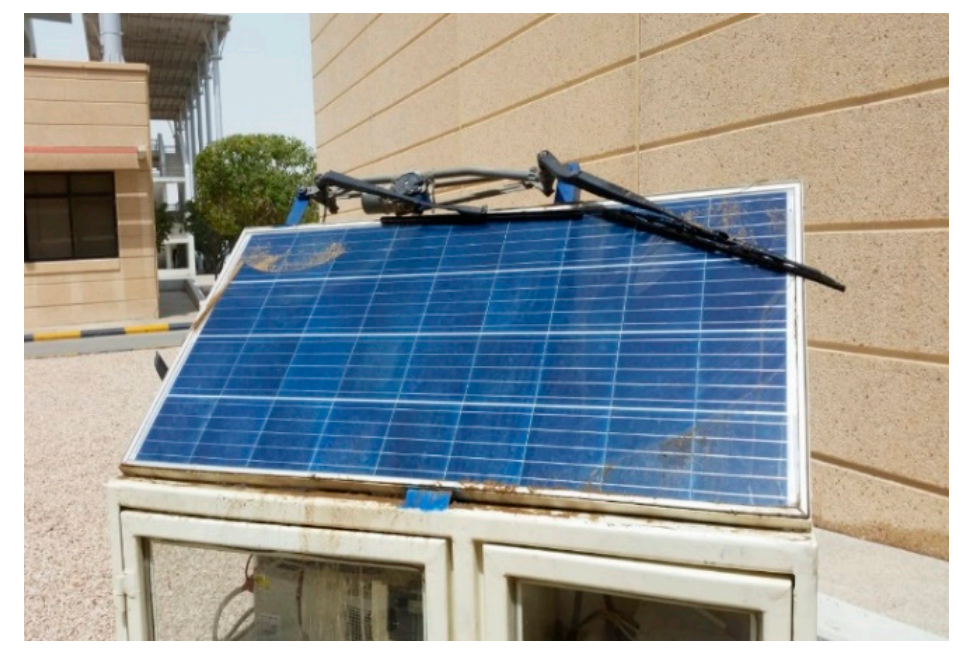

Figure 2. Dust covering most of the area of the solar panel. 
The data for system power and efficiency were calculated at four different times from 9 a.m. to 2 p.m. The results showed discrepancies among four different conditions, namely, hand cleaned, humid, dust, and when cleaning mechanism was initiated. As expected, the worst condition came along with efficiency of $8.9 \%$ for the dust conditions. The cleaning mechanism was very effective in removing the dust, and thus, improving the efficiency to $14.95 \%$ (Table 1). It was indeed expected that the hand cleaned condition would lead to largely enhancing the system's efficiency (i.e., 17.58\%) with respect to the proposed cleaning mechanism (i.e., $14.95 \%$ ), but further attention should be devoted towards the costs required to carry out the manual cleaning. This is expected to be much larger than the initial costs incur for the proposed mechanism manufacturing and installation. In this regard, a simple economical evaluation can be carried out to evaluate the effectiveness of the proposed cleaning mechanism with respect, for instance, to the hand cleaned condition. The initial cost incurred for the installations of the proposed mechanism was around 5336.22 USD. Additionally, considering reasonable and acceptable values of cleaning costs of $0.212 \mathrm{USD} / \mathrm{kWp}$ in the MENA region during the study period [13], some research [17] implied that, if the hand cleaning could be carry out on an hourly basis in each day of a year, the cost incur for the hand cleaning would be $0.212 \times 10 \times 365=7738 \mathrm{USD} / \mathrm{kWp}$ (assuming that the cleaning is carried out $10 \mathrm{~h} /$ day-it is indeed known that the dust accumulation will be relevant on certain days of the year, but this is only for clarification purposes). In addition, one should also consider the fact that the proposed cleaning mechanism requires a predetermined schedule of maintenance interventions, for example, the wiper blade should be checked every six months and replaced once a year (which would cost around 56-89 USD), the rubber squeegee and the metal frames should be checked to avoid problems such as streaking, skipping, chattering, etc. (which would cost around 26-34 USD). This indicates that the cost incurred by the hand cleaning mechanism could be much higher for a large PV system composed of many PV panels. This entails the superiority of the proposed cleaning mechanism that entails a high initial cost and upfront and maintenance costs but a reasonable enhancement in the overall system efficiency. The high initial costs would be indeed compensated with the gains in the system's efficiency.

Table 1. System power and efficiency at 10 a.m.

\begin{tabular}{ccccc}
\hline & Hand Cleaned & Humid & Dust & Mechanism \\
\hline$P_{\text {out }} \cdot[\mathrm{W}]$ & 139 & 130 & 71.1 & 118.56 \\
$P_{\text {solar }} \cdot[\mathrm{W}]$ & 793 & 793 & 793 & 793.2 \\
$\eta \cdot[\%]$ & 17.58 & 16.6 & 8.9 & 14.95 \\
\hline
\end{tabular}

Table 2 reports the sample of calculations of efficiencies at 1 p.m. Again, the cleaning mechanism results showed an effective cleaning technique as efficiency was improved to $12.2 \%$.

Table 2. System power and efficiency at 1 p.m.

\begin{tabular}{ccccc}
\hline & Hand Cleaned & Humid & Dust & Mechanism \\
\hline$P_{\text {out }} \cdot[\mathrm{W}]$ & 105.3 & 107.4 & 55.35 & 100.24 \\
$P_{\text {solar }} \cdot[\mathrm{W}]$ & 823 & 823 & 823 & 823.03 \\
$\eta \cdot[\%]$ & 12.79 & 12.34 & 6.75 & 12.2 \\
\hline
\end{tabular}

Example of calculation is shown below for the solar power input and efficiency:

$$
Q_{\text {solar }}=\varnothing \cdot A=830 \times 0.9916=823.08 \mathrm{~W}
$$

Efficiency $(\eta)$ : efficiency is defined as the ratio of the energy output from solar cell and the input energy from the sun [6] as per Equation (5):

$$
\eta=\frac{Q_{\text {Solar }}}{Q_{\text {in }}}
$$


All four conditions were calculated at different times, and then plotted in Figure 3. The measurements for all the previous four experiments were conducted by having four different setups on 16 May 2019. The solar irradiation varied throughout the period of the measurements from $720-820 \mathrm{~W} / \mathrm{m}^{2}$. Moreover, the dust accumulated was measured by using a dust measuring device PCE-RCM 05 (PCE Instruments, Jupiter, Palm Beach, FL, USA), which is an optimal test instrument to have a constant overview of the fine dust content. In general, as time passed by during the day, the power generated by the solar panel decreased. The cleaning mechanism showed an excellent result in improving the power, especially when it was partially covered with dust. The hand cleaning result was close to the mechanism output data. This confirms the success of the cleaning system, which is thus recommended for any future solar panel installation within the Kingdom.

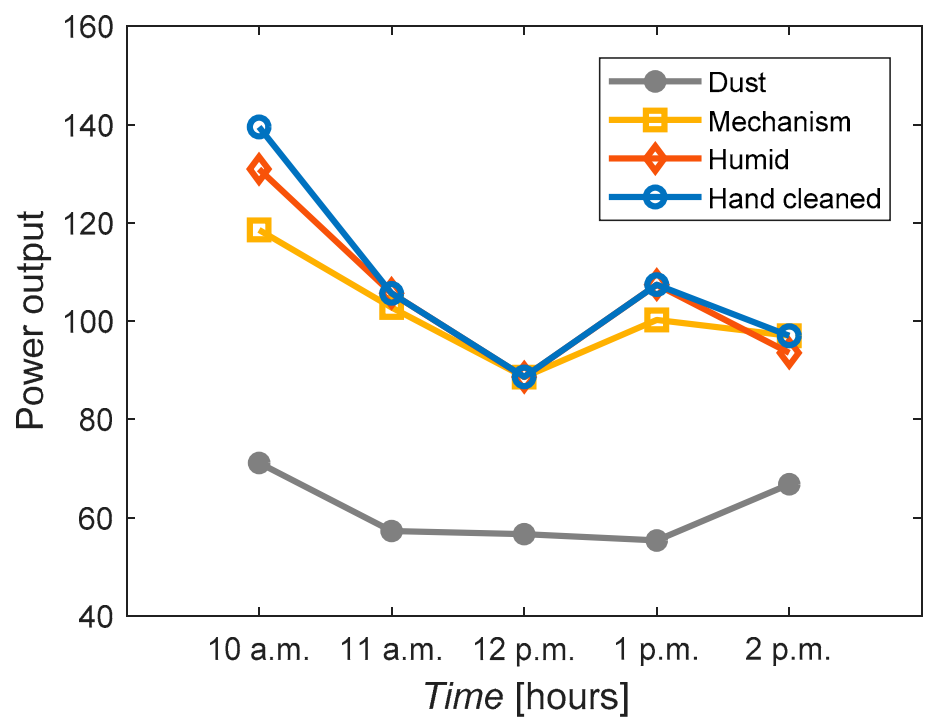

Figure 3. Power output versus time at different conditions.

In addition, the voltage and current for all the conditions were monitored and registered (Table 3). In general, the trend was the same throughout the daytime measurements (9 a.m.-2 p.m.).

Table 3. System voltage and current at 11 a.m.

\begin{tabular}{ccccc}
\hline & Hand Cleaned & Humid & Dust & Mechanism \\
\hline$V$ & 19.15 & 19.15 & 19.15 & 19.05 \\
$I$ & 4 & 4 & 3.25 & 3.9 \\
\hline
\end{tabular}

From all the data collected and the calculations done, a summary of the results showed that the dust on the panels effect greatly on the efficiency of the electrical output. The maximum efficiency was obtained at 10 a.m., since this time the sunlight has the highest coefficient of radiation. The best improvement happened when the automatic solar cleaning system was used. The system is suitable in any commercial and domestic use.

Finally, the performance of a PV cell is defined by the IV-curve, which shows how the current inside the cell varies as a function of the voltage for a given solar irradiance.

Table 4 reports the input power to the solar panel $\left(Q_{\text {solar }}\right)$ and the corresponding output power $\left(Q_{\text {electric }}\right)$ resulted from no cooling versus those resulted with the proposed cooling design in different times in Dhahran region, Saudi Arabia. The normal efficiency of solar panel systems is between $10 \%$ and $15 \%$. After the cooling system being applied in the solar panel; the temperature of solar cell decreased by around $20{ }^{\circ} \mathrm{C}$ and, thus, the efficiency increased by around $7 \%$. For example, the output power between 9 a.m. to 10 a.m. was around $129 \mathrm{~W}$ and it is increased in the next day after ran the cooling system to around $169 \mathrm{~W}$. The conditions for the experiments conducted in Table 4 are 
atmospheric pressure and relative humidity of $78 \%$. Moreover, the dust particles exhibit different shapes with round corners or sharp edges.

Table 4. The result of solar performance $\left(Q_{\text {electric }}\right)$ with and without the cooling system $(t=3600, A=0.0347)$.

\begin{tabular}{ccccc}
\hline Time & $\varnothing$ & $Q_{\text {solar }}$ & $Q_{\text {electricwithoutcooling }}$ & $Q_{\text {electricwithcooling }}$ \\
\hline $9-10$ & 795 & 993.28 & 129.12 & 168.85 \\
$10-11$ & 825 & 1030.76 & 129.81 & 173.16 \\
$11-12$ & 850 & 1062 & 132.75 & 176.29 \\
$12-13$ & 840 & 1049.5 & 131.18 & 177.36 \\
$13-14$ & 805 & 1005.77 & 129.74 & 171.98 \\
\hline
\end{tabular}

For clarification purposes, Figure 4 shows the output power $\left(Q_{\text {electric }}\right)$ before and after the cooler was used during different time slots.

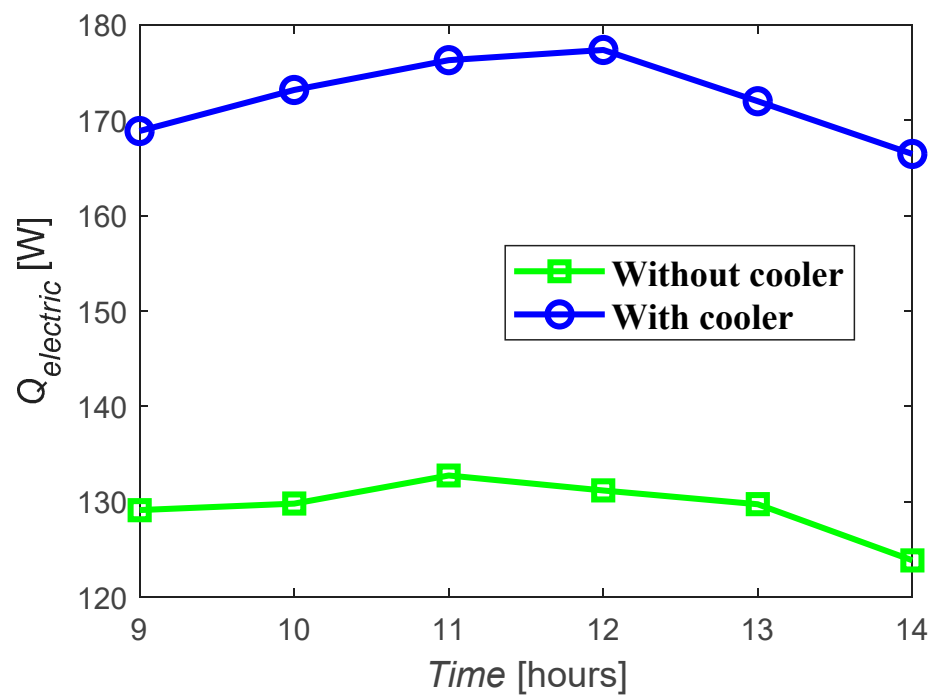

Figure 4. The difference performance of solar panel with (circle marker) and without (square marker) the cooling system.

\section{Conclusions}

The objective of this research was to design an effective cleaning system for the PV panels using water. The cleaning mechanism was chosen taking into consideration the cleaning cost in terms of materials and maintenance. It is recommended to be installed and used on all existing and new panels for numerous commercial and industrial sectors within the Kingdom. In general, the results showed that for the Al-Khobar region, Eastern Province, Kingdom of Saudi Arabia, the efficiency of the solar panels after cleaning was increased from $6 \%$ to an average of $12 \%$ at nominal temperature of $27^{\circ} \mathrm{C}$. In addition, the average power output was increased by $35 \%$ during the day time. The objective of this research was to design an effective cleaning system for the PV panels using water. The cleaning mechanism was chosen taking into consideration the cleaning cost in terms of materials and maintenance. It is recommended to be installed and used on all existing and new panels for numerous commercial and industrial sectors within the Kingdom. In general, the results showed that for the Al-Khobar region, Eastern Province, Kingdom of Saudi Arabia, the efficiency of the solar panels after cleaning was increased from $6 \%$ to an average of $12 \%$ at nominal temperatures of $27^{\circ} \mathrm{C}$. In addition, the average power output was increased by $35 \%$ during the day time. 
Author Contributions: Conceptualization, N.N.; methodology, N.N.; software, N.N.; validation, N.N., W.A.-K., and S.A.-D.; formal analysis, N.N., W.A.-K., and S.A.-D.; investigation, N.N. and W.A.-K.; resources, N.N.; data curation, N.N.; writing — original draft preparation, N.N., W.A.-K., and S.A.-D.; writing-review and editing, N.N., W.A.-K., and S.A.-D.; visualization, N.N., W.A.-K., and S.A.-D.; supervision, N.N.; project administration, N.N. and W.A.-K.; funding acquisition, N.N. All authors have read and agreed to the published version of the manuscript.

Funding: This research received no external funding.

Conflicts of Interest: The authors declare no conflict of interest.

\section{References}

1. Klein, S.A.; Reindl, D.T. Solar Refrigeration. ASHRAE J. 2005, 47, S26-S30.

2. Abdulateef, J.M.; Sopian, K.; Alghoul, M.A.; Sulaiman, M.Y. Review on Solar-Driven Ejector Refrigeration Technologies. Renew. Sustain. Energy Rev. 2009, 13, 1338-1349. [CrossRef]

3. Kim, D.S.; Infante Ferreira, C.A. Solar Refrigeration Options-A State-of-the-Art Review. Int. J. Refrig. 2008, 31, 3-15. [CrossRef]

4. Al-Shamani, A.N.; Yazdi, M.H.; Alghoul, M.A.; Abed, A.M.; Ruslan, M.H.; Mat, S.; Sopian, K. Nanofluids for Improved Efficiency in Cooling Solar Collectors-A Review. Renew. Sustain. Energy Rev. 2014, 38, 348-367. [CrossRef]

5. Parrott, B.; Carrasco Zanini, P.; Shehri, A.; Kotsovos, K.; Gereige, I. Automated, Robotic Dry-Cleaning of Solar Panels in Thuwal, Saudi Arabia Using a Silicone Rubber Brush. Sol. Energy 2018, 171, 526-533. [CrossRef]

6. Khadka, N.; Adhikari, B.; Bista, A.; Shrestha, A. Solar Panel Cleaner Technology: A Review. In Proceedings of the 5th International Conference on Developments in Renewable Energy Technology (ICDRET'18), Kahtmandu University, Nepal, 29-31 March 2018; pp. 1-5.

7. Yadav, A.S.; Pachauri, R.K.; Chauhan, Y.K.; Choudhury, S.; Singh, R. Performance Enhancement of Partially Shaded PV Array Using Novel Shade Dispersion Effect on Magic-Square Puzzle Configuration. Sol. Energy 2017, 144, 780-797. [CrossRef]

8. Bouaddi, S.; Fernández-García, A.; Sansom, C.; Sarasua, J.A.; Wolfertstetter, F.; Bouzekri, H.; Sutter, F.; Azpitarte, I. A Review of Conventional and Innovative-Sustainable Methods for Cleaning Reflectors in Concentrating Solar Power Plants. Sustainability 2018, 10, 3937. [CrossRef]

9. Manju, B.; Bari, A.; Pavan, C.M. Automatic Solar Panel Cleaning System. Int. J. Adv. Sci. Res. Eng. 2018, 4, 26-31.

10. Sreega, R.; Nithyananthan, K.; Nandhini, B. Design and Development of Automated Solar Panel Cleaner and Cooler. Int. J. Electr. Electron. Eng. 2017, 9, 186-197.

11. Tejwani, R.; Solanki, C.S. $360^{\circ}$ Sun Tracking with Automated Cleaning System for Solar PV Modules. In Proceedings of the Conference Record of the IEEE Photovoltaic Specialist, Honolulu, HI, USA, 20-25 June 2010; pp. 002895-002898.

12. Nader, N.A. Design of Solar Panel Intercooled by Refrigeration System. Int. J. E-Learning Educ. Technol. Digit. Media 2019, 5, 30-35. [CrossRef]

13. Al-Kouz, W.; Al-Dahidi, S.; Hammad, B.; Al-Abed, M. Modeling and Analysis Framework for Investigating the Impact of Dust and Temperature on PV Systems' Performance and Optimum Cleaning Frequency. Appl. Sci. 2019, 9, 1397. [CrossRef]

14. Al-Dahidi, S.; Ayadi, O.; Alrbai, M.; Adeeb, J. Ensemble Approach of Optimized Artificial Neural Networks for Solar Photovoltaic Power Prediction. IEEE Access 2019, 7, 81741-81758. [CrossRef]

15. Al-Dahidi, S.; Ayadi, O.; Adeeb, J.; Alrbai, M.; Qawasmeh, R.B. Extreme Learning Machines for Solar Photovoltaic Power Predictions. Energies 2018, 11, 2725. [CrossRef]

16. Rao, R.R.; Mani, M.; Ramamurthy, P.C. An Updated Review on Factors and Their Inter-Linked Influences on Photovoltaic System Performance. Heliyon 2018, 4, e00815. [CrossRef] [PubMed]

17. Hammad, B.; Al-Abed, M.; Al-Ghandoor, A.; Al-Sardeah, A.; Al-Bashir, A. Modeling and Analysis of Dust and Temperature Effects on Photovoltaic Systems' Performance and Optimal Cleaning Frequency: Jordan Case Study. Renew. Sustain. Energy Rev. 2018, 82, 2218-2234. [CrossRef]

18. Menoufi, K. Dust Accumulation on the Surface of Photovoltaic Panels: Introducing the Photovoltaic Soiling Index (PVSI). Sustainability 2017, 9, 963. [CrossRef] 
19. Liu, S.; Yue, Q.; Zhou, K.; Sun, K. Effects of Particle Concentration, Deposition and Accumulation on Photovoltaic Device Surface. Energy Procedia 2019, 158, 553-558. [CrossRef]

20. Markvart, T. Solar Electricity, 2nd ed.; Wiley: Hoboken, NJ, USA, 2000.

21. Nader, A.N.; Alghamdi, M.I.; Alsayed, S.R. Hybrid Air Conditioning, Solar, HVAC, Energy Consumptions. Int. J. Mod. Eng. Res. 2016, 6, 34-42.

22. Hussien, A.A.; Abdullah, M.Z.; Yusop, N.M.; Al-Kouz, W.; Mahmoudi, E.; Mehrali, M. Heat Transfer and Entropy Generation Abilities of MWCNTs/GNPs Hybrid Nanofluids in Microtubes. Entropy 2019, 21, 480. [CrossRef]

23. Hader, M.; Al-Kouz, W. Performance of a hybrid photovoltaic/thermal system utilizing water-Al2O3 nanofluid and fins. Int. J. Energy Res. 2018, 43, 219-230. [CrossRef]

(C) 2019 by the authors. Licensee MDPI, Basel, Switzerland. This article is an open access article distributed under the terms and conditions of the Creative Commons Attribution (CC BY) license (http://creativecommons.org/licenses/by/4.0/). 